\title{
A study assessing the outcome of endoscopic endonasal transsphenoidal excision of pituitary adenoma at a tertiary care institutions - An Initial experience of $\mathbf{3 0}$ cases
}

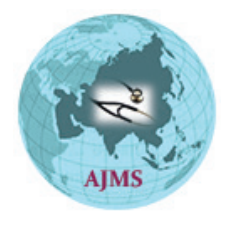

\author{
Sourabh Dixit ${ }^{1}$, Nirmalya Samanta ${ }^{2}$, Suniti Kumar Saha ${ }^{3}$, Nakul Pahwa', Partha Ghosh¹, \\ Abta Bachchan ${ }^{1}$
}

${ }^{1}$ Post Doctoral Trainee, Department of Neurosurgery, Nil Ratan Sircar Medical College, Kolkata, West Bengal, India. ${ }^{2}$ Department of Otorhinolaryngology, Nil Ratan Sircar Medical College, Kolkata, West Bengal, India, ${ }^{3}$ Professor and Head, Department of Neurosurgery, Nil Ratan Sircar Medical College, Kolkata, West Bengal, India

\section{A B S T R A C T}

Background: Endoscopic Endonasal Transphenoidal Pituitary Surgery (EETS), has been proved to be a preferred alternative to conventional surgery because of its salient features like wider, more panoramic field of visualization, improved illumination and mobility of instruments, and an ability to look around anatomical corners using angled lens and minimal invasiveness. The current study was done to analyse the effectiveness and morbidity in the patients operated in our centre by Endoscopic Endonasal Transphenoidal Pituitary Surgery (EETS) done by single team in single centre in 15 months. Aims and Objective: To describe a case series of patients with pituitary adenomas with endoscopic endonasaltranssphenoidal approach, the technique performed and complications in our centre. Materials and Methods: The technique performed in a series of 30 consecutive patients, and description of their complications and the protocol followed to treat these complications. Results: The tumor removal was gross total in $18(60.0 \%)$ patients, subtotal in $8(30.7 \%)$, and partial in $4(7.7 \%)$ patient. Two patients with growth hormone-secreting adenomas had normalization of hormonal status. Four patients developed temporary diabetes insipidus. Four patients developed post-operative CSF rhinorrhea and were managed conservatively. Two patient had recurrence of tumor.one patient had meningitis and one patient expired in perioperative periods. Conclusions: Our experience suggests that the Endoscopic transsphenoidal approach offers a potentially viable and cost economic treatment option in pituitary tumors which are difficult to remove by the standard microscopic approaches. In past one and half year we have witnessed encouraging results without much of the anticipated complications.

Key words: Endoscopic endonasal transsphenoidal approach; Pituitary adenoma; Gross total excision; Subtotal excision

\section{INTRODUCTION}

Pituitary tumors, are one of the most frequent intracranial tumors constituting about $10 \%$ intracranial neoplasm, are clinically classified into 2 groups: functioning and nonfunctioning. Further depending upon the radiological dimensions they are classified into microadenoma and macroadenoma. In the late nineteenth century, the resection of a pituitary tumor via an open craniotomy was first described by Horsley. ${ }^{1}$ Schloffer ${ }^{2}$ reported the transsphenoidal approach in a sella tumor in 1907. Cushing ${ }^{3}$ advocated the sublabial transseptal transsphenoidal technique and Hardy ${ }^{4}$ introduced operative microscope in sellar surgery. The traditional transseptal/translabial approach has long been considered as the standard approach because it is associated with minimal morbidity and mortality. 
Gerard Guiot (1960s) first time introduced Endoscope to transsphenoidal surgery mainly as a microscopeassisted tool to explore the sella cavity for residual tumor. Jankowski (1992) proposed a fully endoscopic approach to pituitary surgery. ${ }^{5}$ The endoscope-guided transsphenoidal surgery was standardized in clinical practice by Jho and Carrau (1997) ${ }^{6}$ and Cappabianca et al., ${ }^{7}$ introducing enhanced illumination and visualization of the lesions. Over more than 2 decades of this technique, most of the neurosurgeons have smooth transition to endoscopy but switching on to endoscopy from open microscopic surgery has been associated with learning curve and experience in endoscopic anatomy. Endoscopic Endonasal Transphenoidal Pituitary Surgery (EETS), has been proved to be a preferred alternative to conventional surgery because of its salient features like wider, more panoramic field of visualization, improved illumination and mobility of instruments, and an ability to look around anatomical corners using angled lens and minimal invasiveness but there is disadvantage of lacking the stereoscopic view obtainable with a microscope. ${ }^{8}$ Problems of instrument maneuverability during procedures have largely been alleviated with the development of newer endoscope-specific instrumentation and the evolution of endoscopic techniques. ${ }^{9,10}$ There is superiority of the binarial endoscopic approach in achieving target surgical freedom and sagittal angular freedom. ${ }^{11}$ High definition 3D endoscopic system may resolve the stereoscopic visualization issue. $^{12}$

The current study was done to analyze the effectiveness and morbidity in the patients operated in our centre by Endoscopic Endonasal Transsphenoidal Pituitary Surgery (EETS) done by single team in single centre in 15 months.

\section{Aims and objectives}

To assess the effectiveness of resection of pituitary adenoma in patients operated by Endoscopic Endonasal Transsphenoidal Pituitary Surgery (EETS).

To assess the incidence of complications and morbidity in patients operated by Endoscopic Endonasal Transsphenoidal Pituitary Surgery (EETS).

\section{MATERIALS AND METHODS}

The current prospective observational study was conducted on 30 patients admitted in our institute with clinicoradiological diagnosis of pituitary adenoma patients and underwent endoscopic endonasal transsphenoidal surgery, conducted by the neurosurgical team between July 2016 and September 2017.

\section{Endocrine assessment}

All endocrine examinations were performed prior to and after surgery and at the time of follow-up consultation. Multiple measurements of plasma growth hormone $(\mathrm{GH})$,insulin-like growth factor-I(IGF-I), prolactin(PRL), adrenocorticotrophic hormone (ACTH), cortisol, $24 \mathrm{~h}$ urinary free cortisol (when Cushing's disease was suspected), thyroid-stimulating hormone (TSH), free thyroxine,luteinizing hormone (LH) and follicle stimulating hormone(FSH), testosterone, and estradiol (E2) levels were investigated.

\section{Neuroradiology}

To evaluate the size and the invasion of the adenoma, all patients underwent magnetic resonance imaging (MRI), with and without administration of the intravenous contrast agent prior to surgery. Tumor size was classified in three categories according to maximum tumor diameter: microadenoma(Less than $10 \mathrm{~mm}$ ); macroadenomas (More than 10mm); and giantadenoma (More than $40 \mathrm{~mm}$ ) and tumors were graded according to Fishers and Hardy classifications.

In addition to this pre-operative Xray skull lateral view, CTscans,and preoperative nasal endoscopy is done to obtain information about the anatomy of sphenoid sinus, sellar floor, nasal sinuses, tuberculum sellae, clivus, position of carotid arteries, optic chiasma, and infundibulum. It is our routine to do a pre operative nasal swab culture.

Pre-operative thorough examination of visual field, fundus and visual acuity is also done and computated perimetry was done to assess the field of vision.

The patient had minimum follow-up period of 3 months and repeat MRI was done on 3 month follow up.

\section{Surgery}

All patients were treated by identical procedure. Under general anesthesia, the patient was placed in the supine position on the operative table and the head tilted back at a $20^{\circ}$ angle. The surgeon was positioned on the right side of the patient and the assistant on the left side. We used a zero or $30^{\circ}$ endoscope. Thorough inspection of both the nasal cavities is done to identify normal structure and any anatomical variation. The middle turbinate was lateralized to get more space for dissection. Sphenoid ostium is identified which lies usually $1-1.5 \mathrm{~cm}$ superior to the choana. Bilateral naso-septal flap was raised. ${ }^{10,12}$ The bilateral endonasal approach provides a wide working area without the need for special instruments.

Endoscope is positioned superiorly at 12 o'clock in right nostril to optimize the available space. Suction is usually 
entered into the 6-o'clock position in the right nose and dissecting instruments can be introduced through the left nostril. Sphenoid ostium is enlarged with Kerrisons rongeurs. Sphenoid rostrum and posterior vomer is removed to open the whole anterior wall of the sphenoid sinus (Figures 1,2) and allows identification of key anatomical landmarks that is medial optico-carotid recess (OCR), carotid protuberance, the sellar face, clival recess and the strut of bone over the superior inter-cavernous sinus (SIS) are be recognized. Any intrasphenoidal septations are removed and sphenoid sinus mucosa is removed and the venous bleeding is controlled by. Bone removal over the sellar face to expose the medial portions of each cavernous sinus and rostro-caudally to expose both the superior and inferior inter-cavernous sinus (Figures 3 and 4 ). Combination of ring curettes and micro dissectors are used to remove tumor within and above the sella.The tumor resection is done through internal debulking, capsular mobilization, and extracapsular dissection from neurovascular structures, along with coagulation and capsule removal.

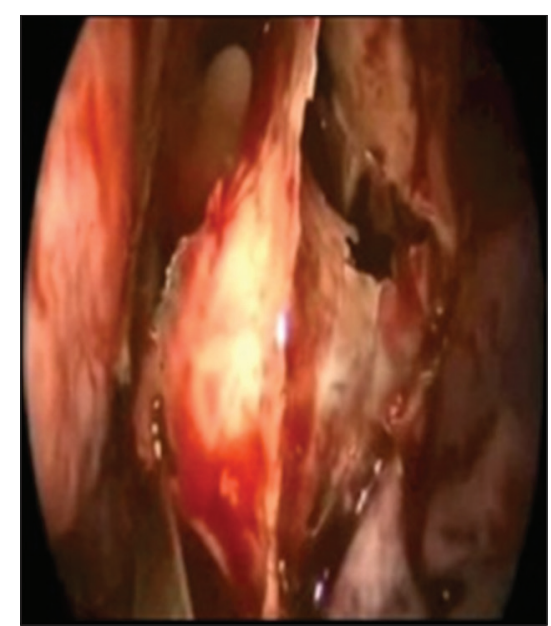

Figure 1: Showing bilateral sphenoid ostium and sphenoid rostrum

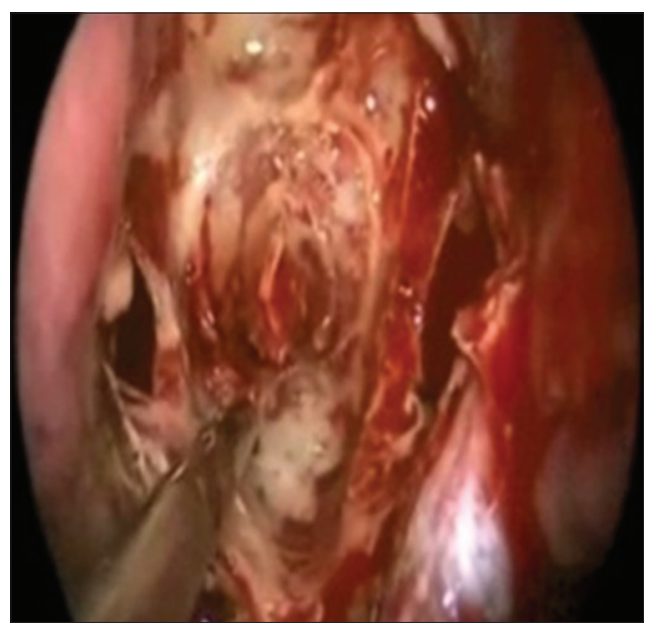

Figure 2: Postsphenoid drilling showing bulging sellar floor
After resection the sella is packed with fat and fascialata graft is overlayed and fibrin glue is applied followed by covering with nasoseptal flap. The bilateral endonasal approach provides a wide working area without the need for special instruments.

In Initial post operative period the patient is managed in ICU and strict input output monitoring is done, repeat routine investigations are sent on next morning along with Urine Osmolality, Serum electrolytes. Depending upon the patient's conditions and morbidites the down stepping is done.

\section{RESULTS}

Regarding age incidence (Table 1, Figure 5) the maximum number of cases i.e $53.33 \%(\mathrm{n}=16)$ were of 31 to 40 years of age. This was followed by $26.66 \%(\mathrm{n}=8)$ incidence in 21-30 yrs age group. This was followed by incidence of $13.33 \%(\mathrm{n}=4)$ in age groups $51-60 \mathrm{yrs}$ and $41-50$ years $(\mathrm{n}=2)$. Regarding the tumor characteristics (Table 2)

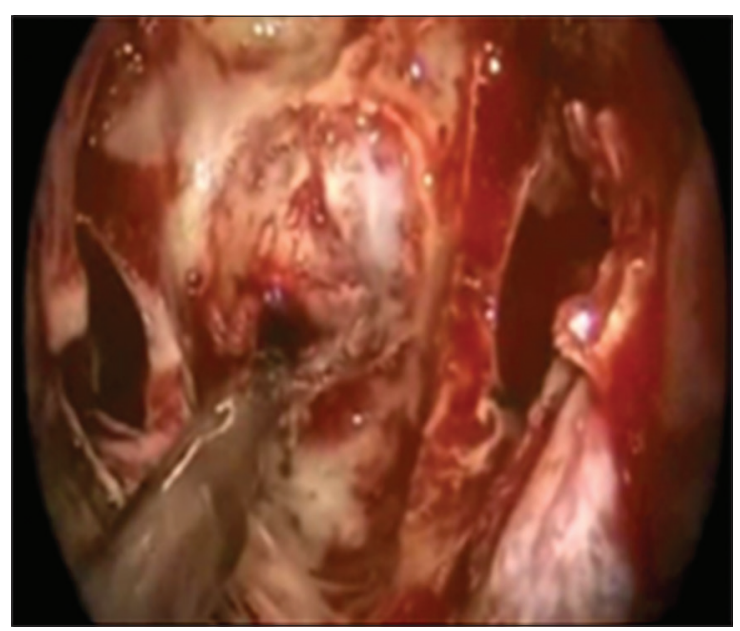

Figure 3: Showing the bulging dura after sellar floor drilling

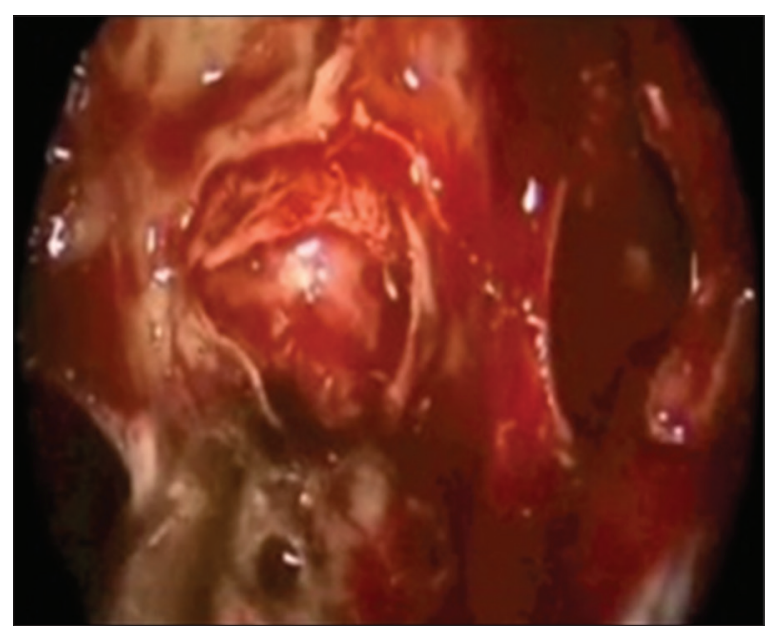

Figure 4: Showing tumor protruding from dural opening 
the maximum number of cases i.e $80 \%(n=24)$ had non secreting adenoma and secreting adenoma was present in $20 \%(n=6)$ patients. Out of which four patients had growth hormone secreting adenoma and two patients had corticotrophic hormone secreting adenoma. Further microadenoma (Table 3, Figures 6 and 7) was present in 4 cases and macroadenoma was present in 16 cases and giant adenoma was present in 10 cases. Wilsons grade I tumor was present in 4 cases, grade II tumor was present in 4 cases, grade III was present in 12 cases and grade IV was present in 10 cases. Suprasellar extension was seen in 22 cases (HARDY'S A, B, C, D) and 4 cases had parasellar cavernous sinus (HARDY'S E) extension. Among the microadenoma gross total excision was done in all 4 cases. Among the macroadenoma (Figures 8 and 9) the gross total excision was done in 10 cases and subtotal excision was achieved in 4 cases and only partial decompression was done in 2 cases. Among the giant adenoma the gross total excision was done in 4 cases and subtotal excision was achieved in 4 cases and only partial decompression was done in 2 cases. So gross total resection (Figures 8 and 9) was done in 18 cases and subtotal resection was done in 8 cases and partial reduction was done in 4 cases.

Preoperatively acromegalic features (Table 4) were shown by 4 patient which improved on post operative period and 2 patient had cushings disease preoperatively which also showed improvement in hormone level post surgery. Preoperative hirsutism was present in 2 female patients which were subsided after surgery.Visual complaints in form of field cuts were present in 16 patients which improved in 8 patients postoperatively. Diminition of vision was present in 6 patients and improved in 2 patients. Papilloedema was present in 18 patients which improved

\begin{tabular}{lcc} 
Table 1: Age wise distribution of patients & \\
\hline 0 - Upto 1 year & 0 & 0 \\
1-10 years & 0 & 0 \\
$11-20$ years & 0 & 0 \\
$21-30$ years & 4 & 4 \\
$31-40$ years & 12 & 4 \\
$41-50$ years & 2 & 0 \\
$51-60$ years & 2 & 2 \\
$>60$ years & 0 & 0 \\
\hline
\end{tabular}

\begin{tabular}{|c|c|}
\hline Adenomas characteristics & $\mathrm{N}(\%)$ \\
\hline Nonfunctioning adenomas & $24(80)$ \\
\hline Hormone-secreting adenomas & $6(20)$ \\
\hline GH-secreting adenomas & $4(13.33)$ \\
\hline ACTH-secreting adenomas & $2(7.66)$ \\
\hline $\begin{array}{l}\text { Prolactinoma mixed GH/PRL } \\
\text { adenomas TSH secreting adenoma }\end{array}$ & Nil \\
\hline
\end{tabular}

in 12 patients in post-operative follow up.Headache was present in all 30 patients and improved in 26 patients in postoperative period.

In immediate postoperative period (Table 5, Figure 10) 4 patients developed transient diabetes insipidus and responded to treatment and there were no permanent diabetes insipidus. 4 patients developed post-operative cerebrospinal fluid (CSF) rhinorrhea which resolved to conservative treatment. Two patients had recurrence of tumor. One patient had meningitis which improved on treatment. One patient had post operative intraventricular haemorrhage and the same patient later expired on $2^{\text {nd }}$ postoperative day.

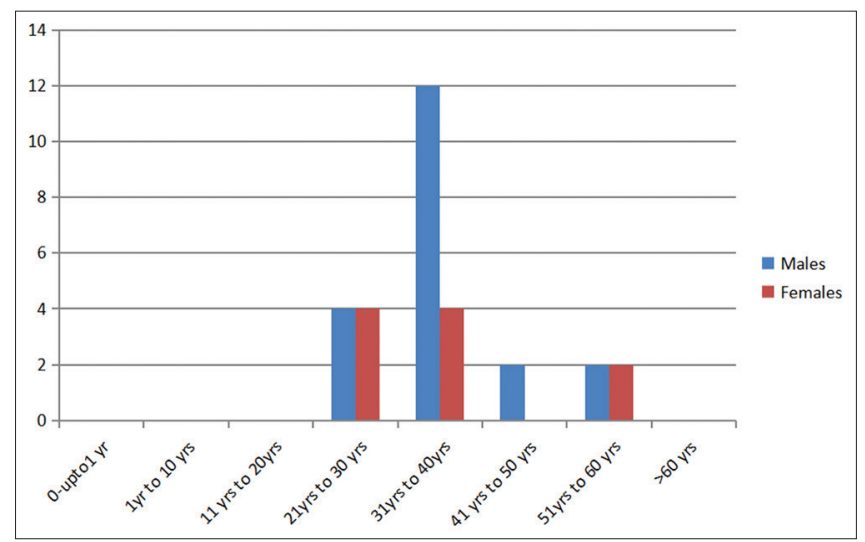

Figure 5: Graph showing age distributions among subjects

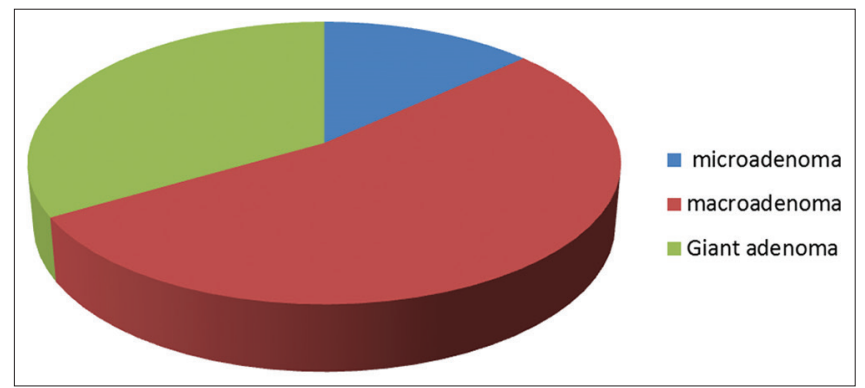

Figure 6: Pie chart showing occurrence of microadenoma, macroadenoma and giant adenoma among subjects

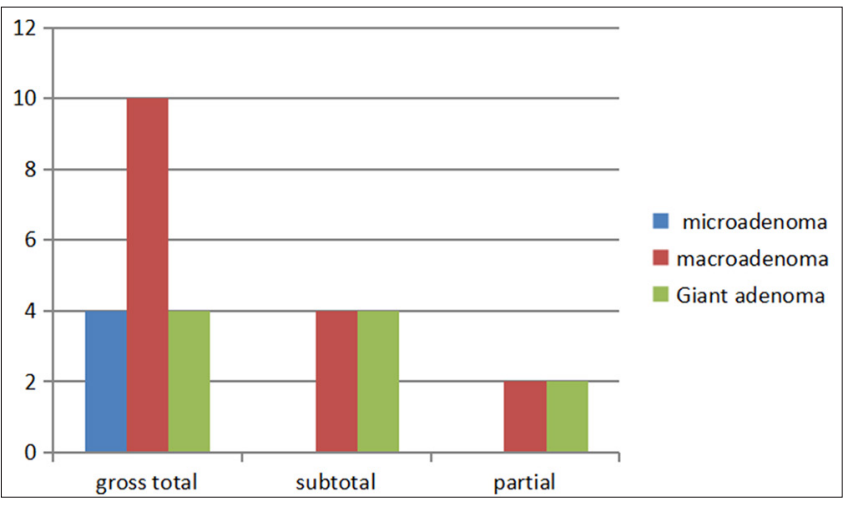

Figure 7: Graph showing surgical resection achieved among cases 
Table 3: Size wise distribution and surgical resection achieved among the patients

\begin{tabular}{|c|c|c|c|c|c|c|c|c|c|c|c|c|c|c|c|c|c|c|c|}
\hline \multirow{3}{*}{ Wilsons Grading } & \multirow{2}{*}{\multicolumn{6}{|c|}{$\begin{array}{l}\text { Microadenoma } \\
(<10 \mathrm{~mm}) \\
4\end{array}$}} & \multirow{2}{*}{\multicolumn{6}{|c|}{$\begin{array}{l}\text { Macroadenoma } \\
(>10 \mathrm{~mm})\end{array}$}} & \multirow{2}{*}{\multicolumn{7}{|c|}{$\begin{array}{l}\begin{array}{l}\text { Giant Adenoma } \\
(>40 \mathrm{~mm})\end{array} \\
10\end{array}$}} \\
\hline & & & & & & & & & & & & & & & & & & & \\
\hline & 0 & $\mathrm{I}$ & II & III & \multicolumn{2}{|c|}{\begin{tabular}{l|l} 
IV & V
\end{tabular}} & 0 & I & II & III & IV & V & 0 & $\mathrm{I}$ & II & III & \multicolumn{2}{|c|}{ IV } & V \\
\hline & - & 4 & - & - & - & - & - & - & 4 & 8 & 4 & - & - & - & - & 4 & \multicolumn{2}{|l|}{6} & - \\
\hline \multirow[t]{2}{*}{ Hardy's Grading } & 0 & A & B & $\mathrm{C}$ & $\mathrm{D}$ & \multirow{2}{*}{$\mathrm{E}$} & & & & & & & 0 & A & B & $\mathrm{C}$ & \multicolumn{2}{|c|}{ D E } & \\
\hline & - & - & - & - & - & & & & & & & & - & - & - & 6 & \multicolumn{3}{|l|}{2} \\
\hline $\begin{array}{l}\text { Type of Resection Gross } \\
\text { Total/Sub Total/Partial }\end{array}$ & \multicolumn{2}{|l|}{4} & - & & \multicolumn{2}{|c|}{ - } & \multicolumn{2}{|l|}{10} & \multicolumn{2}{|l|}{4} & \multicolumn{2}{|l|}{2} & \multicolumn{2}{|l|}{4} & \multicolumn{2}{|l|}{4} & \multicolumn{2}{|l|}{2} & \\
\hline
\end{tabular}

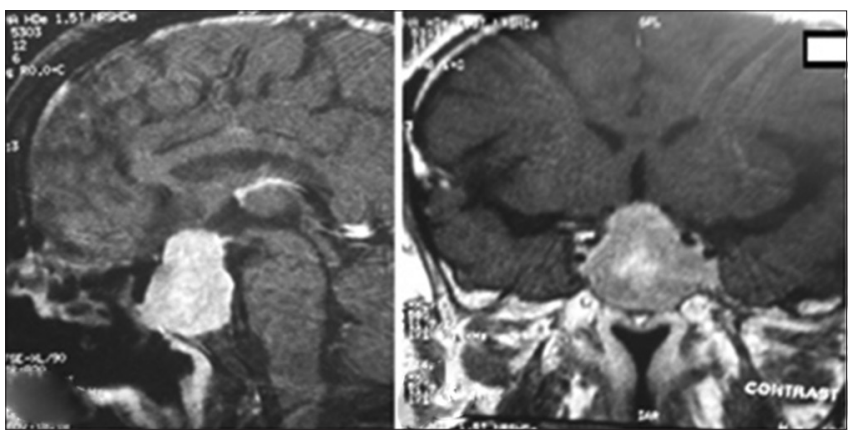

Figure 8A\&B: Showing saggital and coronal T2 weighted images of pituitary macroadenoma with suprasellar extension

\section{DISCUSSION}

Type of adenoma

In our series $80 \%(n=24)$ had non secreting adenoma and secreting adenoma was present in $20 \%(n=6)$ patients. Wang et $\mathrm{al}^{8}$ in there series found $49.5 \%$ patients had non secreting adenoma and $50.5 \%$ had secreting adenoma. In this series $13.33 \%$ had micro adenoma, $53.33 \%$ had macroadenoma and $33.33 \%$ had giant adenoma. Wang et $\mathrm{al}^{8}$ in there series found $21 \%$ had microadenoma, $69.1 \%$ had macroadenoma and $9.9 \%$ had giant adenoma.

\section{Surgical outcome}

Among the microadenoma gross total excision was done in all 4 cases $(100 \%)$. Among the macroadenoma the gross total excision was done in $62.5 \%$ cases and subtotal excision was achieved in $25 \%$ cases and only partial decompression was done in $12.5 \%$ case. Among the giant adenoma the gross total excision was done in $40 \%$ cases and subtotal excision was achieved in $40 \%$ cases and only partial decompression was done in $20 \%$ case. So gross total resection was done in $60 \%$ of total cases and subtotal resection was done in $26.66 \%$ of total cases and partial reduction was done in $13.66 \%$ of total cases.

Wang et $\mathrm{al}^{8}$ in there series achieved grosstotal resection in $98 \%$ micro adenoma, $92 \%$ macroadenoma and \& 76\% giant adenoma.

Asian Journal of Medical Sciences | Jan-Feb 2019 | Vol 10 | Issue 1

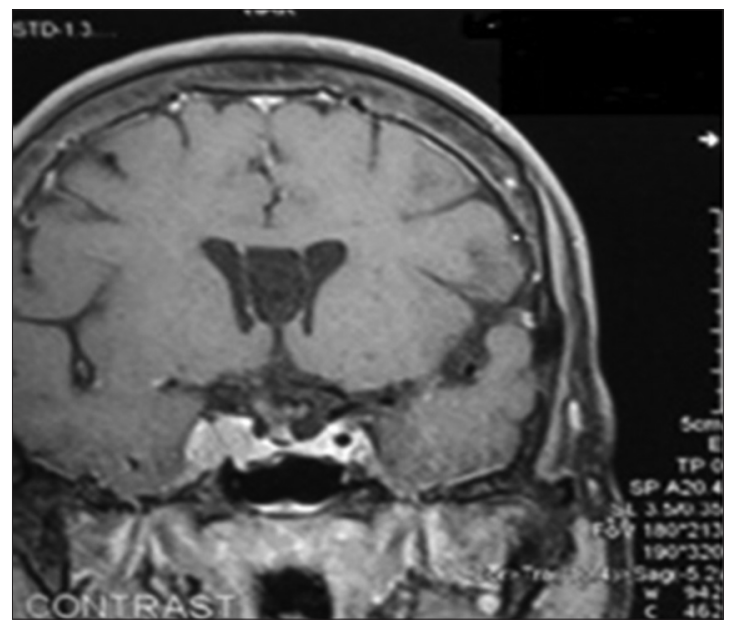

Figure 9: Post operative MRI after 3 months showing gross total excision of macroadenoma

\section{Merits of endoscopic resection}

In metaanalysis done by Gao et $\mathrm{al}^{13}$ found significant difference in gross tumoral removal in endoscopic method as compared to microscopic method. However in one recent study conducted by $\mathrm{H}$. Nishioka ${ }^{9}$ concluded that nonfunctioning adenomas without significant suprasellar or lateral extensions can be effectively removed, either using the microscope or the endoscope, with similar results in experienced hands. For larger tumors, the endoscopic approach may improve outcomes associated with the extent of resection and postoperative complications. In this study it was stressed that for every neurosurgeon, a learning curve is necessary to increase the effectiveness of endoscopic surgery and decrease operation time. Zaidi et al ${ }^{14}$ noted a less experienced surgeon using a fully endoscopic technique was able to achieve outcomes similar to those of a very experienced surgeon using a microscopic technique in a cohort of patients with nonfunctioning tumors smaller than $60 \mathrm{~cm}^{3}$.

Yadav et $\mathrm{al}^{15}$ concluded that most recent reports favor EETS in terms of safety, better quality of life, less nasal symptoms, less blood loss, less operating time, more tumor resection, shorter hospital stay, better endocrinological and 


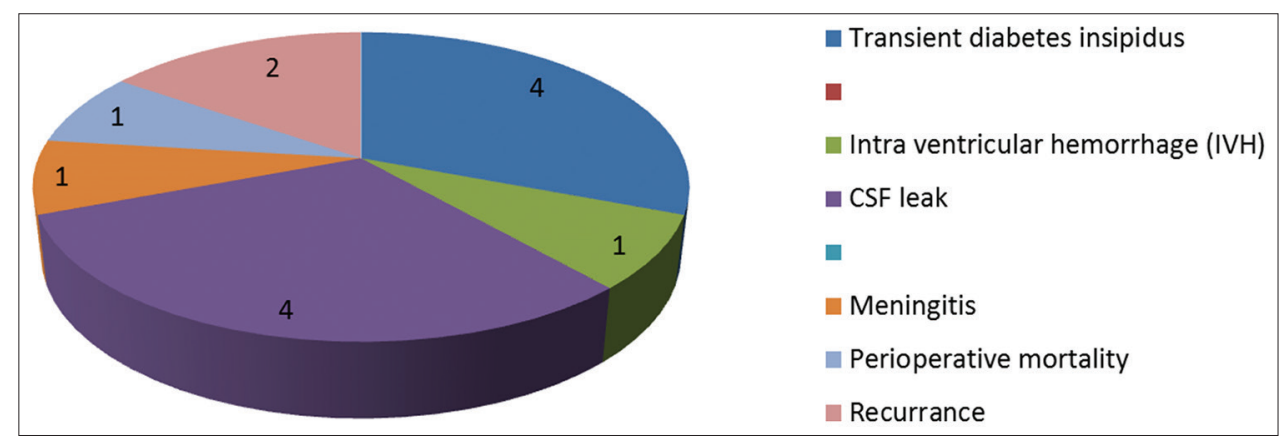

Figure 10: Graph showing occurrence of complications among the subjects

\begin{tabular}{|c|c|c|c|c|c|c|}
\hline & \multicolumn{2}{|c|}{$\begin{array}{l}\text { Microadenoma } \\
(<10 \mathrm{~mm}) \\
(\mathrm{N}=4)\end{array}$} & \multicolumn{2}{|c|}{$\begin{array}{c}\text { Macroadenoma } \\
(>10 \mathrm{~mm}) \\
(\mathrm{N}=16)\end{array}$} & \multicolumn{2}{|c|}{$\begin{array}{c}\text { Giant Adenoma } \\
(>40 \mathrm{~mm}) \\
(\mathrm{N}=10)\end{array}$} \\
\hline \multicolumn{7}{|c|}{ Preoperative signs and symptoms } \\
\hline \multicolumn{7}{|c|}{ Endocrinal Abnormalities } \\
\hline & Pre OP & Post OP & Pre OP & Post OP & Pre OP & Post OP \\
\hline Acromegaly & 4 & Improved & - & - & - & \\
\hline Cushings Disease & 2 & Improved & - & & - & \\
\hline Hirsuitism & - & & 2 & Improved & - & \\
\hline \multicolumn{7}{|l|}{ Visual Abnormalities } \\
\hline Field cuts & - & - & 10 & Improved in 6 & 6 & Improved in 2 \\
\hline Diminition of Vision & - & - & 4 & Improved in 2 & 2 & - \\
\hline Loss of Vision & - & - & 2 & - & 2 & - \\
\hline Papilloedema & - & - & 8 & 6 & 10 & 6 \\
\hline Signs of raised Intracranial & & & & Improved & & Improved \\
\hline pressure & - & & 8 & 6 & 10 & 6 \\
\hline
\end{tabular}

\begin{tabular}{lc}
$\begin{array}{l}\text { Table 5: Postoperative complications among } \\
\text { patients }\end{array}$ & Number (\%) of patients \\
\hline Type of complication & $4(13.33 \%)$ \\
\hline Transient diabetes insipidus & $1(3.33 \%)$ \\
Intra ventricular hemorrhage (IVH) & $4(13.33 \%)$ \\
CSF leak & $1(3.33 \%)$ \\
Meningitis & $1(3.33 \%)$ \\
Perioperative mortality & $2(6.66 \%)$ \\
Recurrance & $\mathrm{Nil}$ \\
Decreased visual acuity & $\mathrm{Nil}$ \\
Epistaxis & $\mathrm{Nil}$ \\
Anterior lobe insufficiency & $\mathrm{Nil}$ \\
SAH & $\mathrm{Nil}$ \\
Hyposmia & $\mathrm{Nil}$ \\
Permanent diabetes insipidus & \\
\hline
\end{tabular}

visual outcome as compared to microscopic technique. They also stressed that EETS like every other surgical technique do have a learning curve. Results are poor in the beginning of the learning curve. This also explains why complications were higher in some endoscopic series as compared to other series. These complications are significantly reduced after achieving this learning curve which could vary between 17 surgeries in O'Malley et a $1^{16}$ series and 50 surgeries in Leach et al. series. ${ }^{17}$

\section{Endocrinological and symptomatic outcome}

Preoperatively acromegalic features were shown by 4 patients who improved on post operative period and 2 patients had Cushings disease preoperatively which also showed improvement in hormone level post surgery. Preoperative hirsutism was present in 2 female patients which was subsided after surgery. Field cuts improved in $50 \%$ patients, diplopia improved in $66.66 \%$ and papilloedema was reduced in $66.66 \%$ cases. Overall visual symptoms improved in $55 \%$ cases. Among the functional adenoma group 2 patients showed recurrence of tumour, one patient had recurrence of Cushings disease and other patient had recurrence of acromegaly.

Wang et $\mathrm{al}^{8}$ in there series achieved Hormonal control, determined in the 3 months after surgery, was achieved in 69 $\%$ cases of ACTH-secreting pituitary adenomas, $66 \%$ cases of GH-secreting pituitary adenomas, $85 \%$ cases of PRL secreting pituitary adenomas, and $86 \%$ cases of TSH secreting adenomas. Visual recovery was acquired in $92 \%$ cases, with the III and VI cranial nerve function restored in $88 \%$ patients.

In study conducted by H. Nishioka ${ }^{9}$ concluded that the surgical outcome of acromegaly by experienced surgeons Asian Journal of Medical Sciences | Jan-Feb 2019 | Vol 10 | Issue 1 
do not differ between endoscopic and microscopic techniques and for ACTH secreting adenoma. The microscopic remission rates of Cushing disease with microadenoma are outstanding in highly experienced hands and have not yet been matched by endoscopic series. Most authors agree that the remission rates of functioning small adenomas do not differ between the approaches. Microscopic procedure probably have more advantage over endoscopic procedure in patients with Cushing's disease with negative MRI and microscopic transsphenoidal cohort had a lower rate of total resection and worse visual outcome than the endoscopic group.

Yadav et $\mathrm{al}^{15}$ concluded that most recent reports favor EETS in endocrinological outcome of endoscopic technique was superior to traditional microsurgical technique.

EETS series reported a high rate of gross-total tumor resection and endocrinological remission in acromegaly patients. Factors affecting the success of the endoscopic surgery were lesion size, suprasellar/parasellar extension, and the degree of sella floor erosion. Trans-sphenoidal pituitary surgery is the primary therapy for Cushing disease because of its potential to produce lasting remission without the need for long-term drug or hormone replacement therapy.

\section{Post operative complications}

In the present series $13.33 \%$ patients developed temporary diabetes insipidus. $13.33 \%$ developed post-operative CSF rhinorrhea and were managed conservatively. One patient $(3.33 \%)$ had meningitis which resolved on antibiotic treatment and one patient had (3.33\%) had post operative intraventricular haemorrhage in third ventricle and the same patient died on 2ndpost operative day. Other complications as mentioned in several other studies $8,9,13,15$ like Permanent diabetes insipidus, Decreased visual acuity, Epistaxis, Anterior lobe insufficiency, SAH, Hyposmia, Coma were not encounterred in the patients in this study.

Wang et $\mathrm{al}^{8}$ in there series observed Transient diabetes insipidus in $6.35 \%$ and permanent diabetes insipidus in $0.69 \%$ requiring vasopressin therapy and clinical follow-up.

Postoperative CSF leakage was observed in $0.6 \%$ patients. A second operation was performed in these patients to reconstruct the sellae and the double layer of dura form and free fascia lata grafts placed in both the intradural and epidural space supported by fat tissue with Lumbar drainage was maintained for 5-7 days after the operation. Meningitis was reported in $1.05 \%$ cases.

In metaanalysis done by $\mathrm{Gao}$ et $\mathrm{al}^{13}$ there was no significant difference between the two techniques in the incidence rates of meningitis, diabetes insipidus, cerebrospinal fluid leak, epistaxis or hypopituitarism.

In study conducted by $\mathrm{H}$. Nishioka ${ }^{9}$ concluded that the reported incidence of postoperative CSF rhinorrhea following endoscopic pituitary surgery usually ranges between 0.7 and $12 \%$ and associated a higher risk of intraoperative CSF leakage in endoscopic approach, the postoperative leak rates are at least equivalent if not superior to lower than those in microscopic surgery in the recent literature.

The risk for permanent diabetes insipidus with endoscopic surgery accounted for between 0.7 and $8.5 \%$. Yadav et $\mathrm{al}^{15}$ concluded that Complication rates were low in most endoscopy group as compared to the microscopic technique. Post-operative CSF leaks, delayed nasal bleeding, sphenoid sinusitis, carotid artery injury, and meningitis occurred in $2.6 \%, 1.9 \%, 1.6 \%, 0.9 \%$, and $0.6 \%$, respectively. Endocrinological complications were observed in $17.9 \%$ cases out of which anterior lobe insufficiency was seen in $11.6 \%$ and diabetes insipidus in $6.3 \%$ cases. Emptysella syndrome, diabetes insipidus, CSF rhinorrhea, postoperative intracapsular hematoma were also reported.A higher incidence of post-operative CSF leak was noted in the endoscopic approach as compared to the microscopic technique due to large lesions with higher proportions of suprasellar tumors and also due to initial learning curve in the endoscopy group. On the other hand, low CSF leak was also reported in the endoscopic group.

In our study we had $1(3.33 \%)$ mortality which was due to post operative Third ventricular bleed and patient expired on $2^{\text {nd }}$ post operative day. Nishioka9 stated mortality in less than $1 \%$ cases in their series.Edson Rocha et $\mathrm{al}^{18} \mathrm{had}$ reported a mortality rate of $7.1 \%$ in their series.

\section{Mean operating time}

The mean operating time in our series was 212.66 minutes and mean hospital stay was 4.3 days. Gao et $\mathrm{al}^{13}$ in their metaanalysis found that the mean operating time was 173 minutes and mean hospital stay was 3.8 days.

\section{Rationale of EETS in developing countries}

Economic aspect of this transition has been searched by various authors and the rationale of endoscopic surgeries in developing countries like India lies in fact that various studies have shown that EETS is associated with decreased mean operative time, length of hospital stay, morbidity ${ }^{13,14}$ and has proven to be a cost effective intervention. ${ }^{9}$ So early transition to endoscopic surgery is economically more reasonable.

An important limitation of our study was small sample size and short period of follow up which could have 
been a hindrance in statistical calculations and calculating complication rates.

\section{CONCLUSION}

In present study we have got encouraging results in form of gross tumor resection rates, endocrinological and symptomatic improvements among patients and fewer complications in intraoperative and post operative periods. Although there is limitation of size of this study and also learning curve but still from our experience of this naïve technique for past one year we conclude that EETS is valuable and safe, and cost effective option to microsccopic surgery for pituitary adenoma. Also with time as our familiarity and experience wiyh this technique will increase, we expect better results.

\section{REFERENCES}

1. Horsley V. Remarks on Ten Consecutive Cases of Operations upon the Brain and Cranial Cavity to Illustrate the Details and Safety of the Method Employed. British Medical Journal. 1887; 1(1373):863-865.

2. Schmidt RF, Choudhry OJ, Takkellapati R, Eloy JA, Couldwell WT and Liu JK. Hermann Schloffer and the origin of transsphenoidal pituitary surgery. Neurosurgical Focus Aug 2012; 33(2):E5.

3. Cushing H. The Pituitary Body and Its Disorders: Clinical States Produced by Disorders of the Hypophysis Cerebri. Philadelphia: JB Lippincott, 1912

4. Hardy J. Transsphenoidal hypophysectomy 1971. J Neurosurg 2007; 107:458-471.

5. Jankowski R, Auque J, Simon C, Marchai JC, Hepner H and Wayoff M. Endoscopic Pituitary Tumor Surgery. The Laryngoscope 1992; 102(2).

6. Jho HD and Carrau RL. Endoscopic endonasal transsphenoidal surgery: experience with 50 patients. Journal of Neurosurgery 1997; 87(1): 44-51.

7. Cappabianca P, Cavallo LM, Colao A, Del Basso De Caro M, Esposito F, Cirillo S, etal. Endoscopic Endonasal Transsphenoidal Approach: Outcome Analysis of 100 Consecutive Procedures. Min - Minimally Invasive Neurosurgery 2002; 45(4): 193-200.
8. Wang F, Zhou T, Wei S, Meng X, Zhang J, Hou Y and Sun G. Endoscopic endonasal transsphenoidal surgery of 1,166 pituitary adenomas. Surgical Endoscopy 2015; 29(6): 1270-1280.

9. Nishioka H. Recent Evolution of Endoscopic Endonasal Surgery for Treatment of Pituitary Adenomas. Neurologia MedicoChirurgica 2017; 57(4): 151-158.

10. Singh H, Essayed WI, Cohen-Gadol A, Zada G and Schwartz TH. Resection of pituitary tumors: endoscopic versus microscopic. J Neurooncol 2016; 130: 309.

11. Elhadi AM, Hardesty DA, Zaidi HA, Kalani MYS, Nakaji P, White W, et al. Evaluation of Surgical Freedom for Microscopic and Endoscopic Transsphenoidal Approaches to the Sella. Neurosurgery 2015;11 Suppl 2:69-78; discussion 78-79.

12. Tabaee A, Anand VK, Fraser JF, Brown SM, Singh A and Schwartz TH. Three- Dimensional Endoscopic Pituitary Surgery. Operative Neurosurgery 2009; 64, ons288-ons295.

13. Gao Y, Zhong C, Wang Y, Xu S, Guo Y, Dai C, et al. Endoscopic versus microscopic transsphenoidal pituitary adenoma surgery: a meta-analysis. World Journal of Surgical Oncology 2014; 12(1): 94.

14. Zaidi HA, Awad AW, Bohl MA, Chapple K, Knecht L, Jahnke H, et al. Comparison of outcomes between a less experienced surgeon using a fully endoscopic technique and a very experienced surgeon using a microscopic transsphenoidal technique for pituitary adenoma. Journal of Neurosurgery 2016; 124(3): 596-604.

15. Yadav $Y$, Sachdev S, Parihar V, Namdev $\mathrm{H}$ and Bhatele P. Endoscopic endonasal trans-sphenoid surgery of pituitary adenoma. Journal of Neurosciences in Rural Practice 2012; 3(3): 328.

16. O'Malley BW, Grady MS, Gabel BC, Cohen MA, Heuer GG, Pisapia J, et al. Comparison of endoscopic and microscopic removal of pituitary adenomas: single-surgeon experience and the learning curve. Neurosurgical Focus 2008; 25(6): E10.

17. Leach P, Abou-Zeid AH, Kearney T, Davis J, Trainer PJ and Gnanalingham KK. Endoscopic Transsphenoidal Pituitary Surgery: Evidence of an Operative Learning Curve. Neurosurgery 2010; 67(5): 1205-1212.

18. Rocha CE, Rafael L, Cândido FC, André AM and Alberto LJ. Surgical outcomes of the endoscopic endonasal transsphenoidal approach for large and giant pituitary adenomas: institutional experience with special attention to approach-related complications. Arq Neuro-Psiquiatr. [Internet]. 2016 May [cited 2018 Sep 28]; 74(5): 388-395.

\section{Authors Contribution:}

SD- Drafting of manuscript, collection of data, Proof reading, operating assistant; NS- Design of study, main operating surgeons, selection of cases, drafting of script; SKS- Design of study, main operating surgeons, selection of cases, drafting of script; NP- clinical photograph collection of data, Proof reading, operating assistant; PG- collection of data, Proof reading, operating assistant; AB- collection of data, Proof reading, operating assistant.

Work attributed to: Department of Neurosurgery, NRS Medical College Kolkata (WB) India

Orcid ID:

Dr. Sourabh Dixit- (D) http://orcid.org/0000-0003-1085-7000

Dr. Nirmalya Samanta- (i) https://orcid.org/0000-0001-5536-1493

Dr. Suniti Kumar Saha- (D) https://orcid.org/0000-0002-6217-9355

Dr. Nakul Pahwa- (1) http://orcid.org/0000-0003-2992-9211

Dr. Partha Ghosh- (D https://orcid.org/0000-0002-8510-7776

Dr. Abta Bachchan - (D) https://orcid.org/0000-0002-1398-004X

Source of Support: Nil, Conflict of Interest: None. 